\title{
Psychological impact of suspension/postponement of fertility treatments on infertile women waiting during COVID pandemic
}

\author{
Parul Jaiswal, MD¹, Reeta Mahey, MD, DNB ${ }^{1}$, Shalini Singh, DM, MD², Perumal Vanamail, PhD', \\ Monica Gupta, DM, MD'1 , Rohitha Cheluvaraju, MD, DNB ${ }^{1}$, J B Sharma, MD, FRCOG ${ }^{1}$, \\ Neerja Bhatla, MD, FICOG, FAMS ${ }^{1}$ \\ Departments of ${ }^{1}$ Obstetrics and Gynaecology and ${ }^{2}$ Psychiatry, All India Institute of Medical Sciences, New Delhi, India
}

\section{Objective}

To assess the psychological impact of suspension/postponement of various fertility treatments on infertile women during the coronavirus disease 2019 (COVID-19) pandemic.

\section{Methods}

This was a cross-sectional study conducted as an online survey among infertile women consulting either through teleconsultation or physical consultation at a fertility clinic of a tertiary care referral unit. A validated questionnaire was given as a WhatsApp link to the women who were consulting for the resumption of services. Questions asked were based on their socio-demographic parameters, fertility treatment at the time of suspension, anxiety (selfreported) and stress (perceived stress scale-4, PSS-4) due to delay in treatment, psychosocial effect of pandemic, and wishes regarding the resumption of fertility services.

\section{Results}

Of 430 patients who received the questionnaire, 250 completed the survey (response rate: $58 \%$ ). The mean age of participants was $29.26 \pm 4.18$ years and the majority $(70.4 \%)$ had lower socioeconomic status. The average PSS-4 score was $7.8 \pm 0.71$, and the prevalence of self-reported anxiety was $72 \%$. Those who suffered migration during the pandemic had significantly higher PSS-4 scores, and increasing age was associated with increased self-reported anxiety due to the suspension of fertility services. The top three priorities reported were infertility and treatment delay $(48.4 \%)$, job loss (19.2\%), and the risk of contracting COVID-19 infection (16\%). The degree of spousal support was significantly correlated with lower PSS-4 scores $(r=-0.30, P<0.01)$. On multivariate logistic analysis, duration of infertility, delay in treatment due to suspension of services, and fear of COVID-19 infection were significant predictors of stress and anxiety.

\section{Conclusion}

This study emphasizes the need to investigate psychosocial health and to provide psychological support to this vulnerable population in addition to triaging fertility treatments in a phased manner.

Keywords: Infertility; COVID-19; Mental health; Health services accessibility; In-vitro fertilisation

Received: 2021.07.27. Revised: 2021.10.19. Accepted: 2021.11.15.

Corresponding author: Reeta Mahey, MD, DNB

Department of Obstetrics and Gynaecology, All India Institute of Medical Sciences, Sri Aurobindo Marg, Ansari Nagar, New Delhi 110029, India E-mail: reetamahey52@gmail.com

https://orcid.org/0000-0003-4938-4466 


\section{Obstetrics \& Gynecology Science}

Vol. 65 , No. 2, 2022

\section{Introduction}

Since the declaration of coronavirus disease 2019 (COVID-19) as a pandemic on March 11, 2020 by WHO [1], the whole world has struggled to manage this calamity, and there has been a deviation in the whole health system to manage COVID-19 cases. Immediate recommendations were made by European Society of Human Reproduction and Embryology and American Society of Reproductive Medicine (March 2020) to withhold all in-vitro fertilisation cycles cycles except for fertility preservation cycles, cancel all embryo transfers, and suspend elective operations because of the unknown effect of this viral infection on the developing fetus [2]. Later on, as the pandemic progressed, the recommendations were modified in order to allow slow reopening of clinics depending upon the burden of cases in different countries.

Global crises such as pandemics, wars, and natural disasters may lead to massive psychological impacts on the general population, leading to stress-related disorders [3]. Infertility affects the psychological, social, and emotional aspects of most infertile couples and is considered one of the most stressful life events [4]. In addition, fertility treatments, prolonged treatment, and financial costs put extra burden on couples seeking fertility treatments [5]. Additional contributors to this stress are societal pressures, socio-economic status, and other unexpected stressors such as pandemics [6]. Being a low-middle income country (LMIC), a major portion of the rural population in India works in metropolitan cities, and the lockdown imposed during the pandemic led to huge internal migration and job loss in this segment of the population. This has created a significant financial crisis and psychosocial morbidity among people [7].

All elective services were shut in March 2020 at our tertiary care referral center, leaving the infertile couples hopeless and uncertain about the resumption of services.

As the case numbers decreased, services were opened on a restricted basis from September 2020, and infertile couples started consulting physically in addition to teleconsultations. However, the resumption of services was restricted to social distancing norms, so patients experienced extended waiting periods, during which time they suffered from other impacts of the pandemic, including jobs loss, migration, and financial losses.

Most studies addressing stress and anxiety due to delays in fertility treatments and clinic closure are from Western countries, where the COVID-19 pandemic struck early on $[8,9]$, and data from LMIC are sparse [10]. This study hence aimed to evaluate stress and anxiety among infertile women waiting for the resumption of services and factors affecting psychological morbidity in a LMIC.

\section{Materials and methods}

The present cross-sectional study was conducted at the fertility clinic of a tertiary care referral hospital in India. The participants were infertile women who consulted either through teleconsultation or physical appointments. Participation was voluntary and anonymous. After receiving ethical approval from the Institute Ethics Committee (IEC-459/May 22, 2020; RP-10/2020; OP-41/January 8, 2021), a Google link to the validated questionnaire was prepared and sent to participants who were willing to participate in the study (JanuaryMarch 2021). The survey was conducted prior to the start of the vaccine administration to this age group.

Inclusion criteria were infertile women consulting in fertility clinics, aged 21-40 years, and who were able to understand English or Hindi. These women were undergoing evaluation for infertility and were waiting for intrauterine insemination, in-vitro fertilisation, or fertility-enhancing endoscopic surgeries. We chose not to exclude participants due to pre-existing mental illness. Instead, we carried out a subgroup analysis of patients with a history of anxiety and/or depressive disorder. The link for this questionnaire was sent as a WhatsApp link accordingly. Preliminary information was sent as a message along with the Google form, and women were asked to fill the same either on their own or with the help of a spouse. The online survey was preliminarily sent to 430 women over a period of three months. Women who were illiterate, but were willing to participate were asked the survey questions offline by one of the researchers.

\section{Questionnaire}

The questionnaire was adapted from our previously published study and it was further modified with the help of a psychiatrist as a co-investigator and after review of the literature [11]. Those who had participated in the previous questionnaire were accordingly excluded from the study. The questionnaire was divided into the following sections: the first section was about socio-demographic parameters, including age, dura- 


\section{Obstetrics \& Gynecology Science}

Parul Jaiswal, et al. Suspension of fertility services

tion and type of infertility, and status of fertility treatment at the time of suspension. The modified Kuppuswamy score was used to assess socioeconomic status (SES) [12]. The second part consisted of the effect of the COVID-19 pandemic on personal and socio-economic parameters, job loss/financial constraints, history of COVID-19 infection to self/relative, and any family/friend loss due to COVID. Participants were asked about their past history of diagnosed anxiety and depressive disorder, and a self-rating score ("scale of 1 to 10") was used to measure anxiety experienced due to delay in their treatment following ongoing restrictions and the impact of the pandemic on their future pregnancy. On this scale, one indicated that they 'did not feel anxious at all', while a score of 10 indicated that they 'felt extremely anxious'.

The next part was regarding the option of their willingness to start treatment if given the choice. The Hindi version of the Perceived Stress Scale-4 (PSS-4 Hindi) was used to measure the perceived stress due to the pandemic and its impact on ART. The scale uses a 4-point Likert scale from "never" to "very often" to assess perception of stress in the last one month at the time of assessment. The lowest and highest scores were 0 and 16, respectively, with higher scores indicating a higher degree of perceived stress. To assess the reliability of the questionnaire items, we computed the Cronbach alpha coefficient, which was 0.63 in our study.

Since the study was carried out on a time-bound basis through an online survey, we could not carry out proper sample size calculation, and hence convenience sampling was used accordingly. We performed a post-doc power analysis. The prevalence of self-reported anxiety in our study was $72 \%$ (180/250). Based on an expected prevalence of $60 \%$ (null value) and with a sample size of 250 , the prevalence obtained $(72 \%)$ yielded more than $95 \%$ power at a level of significance of $P=0.045$.

\section{Statistical analysis}

To test for normality assumptions of data, we used the Kolmogorov-Smirnov test. The descriptive measures are presented as mean \pm standard deviation (SD) for normally distributed data. To test the mean values, we used Student's t-test or ANOVA as appropriate. Categorical data are presented as frequency and percentage values. We used Chisquare/Fisher's exact test as appropriate for the comparison of frequency values across the categories. To assess the linear association between the two variables, we carried out bivari-
Table 1. Socio-demographic and clinical features of the participants $(n=250)$

\begin{tabular}{|c|c|c|}
\hline Characteristic & Frequency & Percentage (\%) \\
\hline \multicolumn{3}{|l|}{ Age $(y r)$} \\
\hline$\leq 25$ & 51 & 20.4 \\
\hline $26-30$ & 117 & 46.8 \\
\hline $31-35$ & 63 & 25.2 \\
\hline$\geq 36$ & 19 & 7.6 \\
\hline \multicolumn{3}{|c|}{ Education status of patient } \\
\hline Illiterate & 11 & 4.4 \\
\hline Primary & 13 & 5.2 \\
\hline Secondary & 77 & 30.8 \\
\hline Graduate and above & 149 & 59.6 \\
\hline \multicolumn{3}{|l|}{ SES } \\
\hline Upper (SES I) & 11 & 4.4 \\
\hline Middle (SES I//II) & 63 & 25.2 \\
\hline Lower (SESIVN) & 176 & 70.4 \\
\hline \multicolumn{3}{|l|}{ Type of family } \\
\hline Joint & 141 & 56.4 \\
\hline Nuclear & 109 & 43.6 \\
\hline \multicolumn{3}{|l|}{ Type of residence } \\
\hline Urban & 204 & 81.6 \\
\hline Rural & 46 & 18.4 \\
\hline \multicolumn{3}{|l|}{ Type of infertility } \\
\hline Primary & 185 & 74.0 \\
\hline Secondary & 65 & 26.0 \\
\hline \multicolumn{3}{|l|}{ Duration of infertility (yr) } \\
\hline $1-5$ & 127 & 50.8 \\
\hline $6-10$ & 102 & 40.8 \\
\hline $11-15$ & 20 & 8.0 \\
\hline $16-20$ & 01 & 0.4 \\
\hline \multicolumn{3}{|l|}{ Cause of infertility ${ }^{\text {a) }}$} \\
\hline Tubal & 61 & 24.4 \\
\hline Endometriosis & 17 & 6.8 \\
\hline PCOS & 40 & 16.0 \\
\hline DOR & 11 & 4.4 \\
\hline Male & 22 & 8.8 \\
\hline Unexplained & 59 & 23.6 \\
\hline Under evaluation & 66 & 26.4 \\
\hline \multicolumn{3}{|c|}{$\begin{array}{l}\text { Status of treatment at start of } \\
\text { pandemic }\end{array}$} \\
\hline Under evaluation & 109 & 43.6 \\
\hline Ovulation induction & 65 & 26.0 \\
\hline Waiting for surgery & 22 & 8.8 \\
\hline Waiting for IVF & 89 & 35.6 \\
\hline Previously failed IVF & 21 & 8.4 \\
\hline
\end{tabular}

SES, socio-economic status; PCOS, polycystic ovarian syndrome; DOR, diminished ovarian reserve; IVF, in-vitro fertilisation.

${ }^{\text {a) }} \mathrm{n}>250$ as patients had more than one factor of infertility and previously failed IVF patients were also waiting for their next cycle. 


\section{Obstetrics \& Gynecology Science}

Vol. 65, No. 2, 2022

ate correlation analysis. To determine the significant variables that contributed to the variation in overall PSS-4 and anxiety scores, we performed multiple linear regression analysis using a stepwise procedure. Univariate and multivariate logistic regression analyses were used to determine the risk factors associated with self-reported anxiety outcomes. The odds ratio with a $95 \%$ confidence interval $(\mathrm{Cl})$ expressed covariate effects. Statistical significance was set at $P<0.05$.

\section{Results}

A total of 283 responses were received at the end of 3 months from the 430 women. After removing 33 incomplete entries, 250 women were enrolled in the final analysis (response 58\%). Table 1 describes the sociodemographic details of the study participants. The mean age of participants was $29.26 \pm 4.18$ years, and $70.4 \%$ had lower SES. More than half $(56.4 \%)$ of the participants lived in joint families, and the majority $(81.6 \%)$ resided in urban areas. The average duration of infertility was $5.84 \pm 0.71$ years, and one third of these women were waiting for their IVF cycle to be started at

Table 2. Correlation of clinical and psychosocial variables of participants with anxiety and stress during pandemic (as measured by PSS-4)

\begin{tabular}{|c|c|c|c|c|c|c|}
\hline & \multicolumn{2}{|c|}{$\begin{array}{l}\text { How anxious are you } \\
\text { about the delay in treat- } \\
\text { ment due to suspension of } \\
\text { fertility services (measured } \\
\text { on a scale of } 1 \text { to } 10 \text { ) }\end{array}$} & \multicolumn{2}{|c|}{$\begin{array}{l}\text { How anxious are you } \\
\text { about the risk of infection } \\
\text { during hospital visit (mea- } \\
\text { sured on a scale of } 1 \text { to } 10 \text { ) }\end{array}$} & \multicolumn{2}{|c|}{ PSS-4 scores } \\
\hline & Value & $P$-value & Value & $P$-value & Value & $P$-value \\
\hline \multicolumn{7}{|l|}{ Infertility type } \\
\hline Primary $(n=185)$ & $5.61 \pm 3.39$ & 0.515 & $4.29 \pm 3.11$ & 0.901 & $4.00 \pm 2.61$ & 0.584 \\
\hline Secondary $(n=65)$ & $5.29 \pm 3.12$ & & $4.23 \pm 3.06$ & & $4.21 \pm 2.75$ & \\
\hline \multicolumn{7}{|c|}{$\begin{array}{l}\text { Did you suffer migration during } \\
\text { pandemic? }\end{array}$} \\
\hline Yes $(n=21)$ & $5.81 \pm 3.01$ & 0.682 & $5.00 \pm 3.34$ & 0.268 & $5.33 \pm 3.24$ & 0.021 \\
\hline No $(n=229)$ & $5.50 \pm 3.35$ & & $4.21 \pm 3.08$ & & $3.94 \pm 2.56$ & \\
\hline \multicolumn{7}{|c|}{$\begin{array}{l}\text { Have you or your spouse lost your } \\
\text { job during pandemic? }\end{array}$} \\
\hline Yes $(n=104)$ & $5.53 \pm 3.22$ & 0.985 & $4.06 \pm 3.04$ & 0.357 & $4.29 \pm 2.68$ & 0.232 \\
\hline No $(n=146)$ & $5.52 \pm 3.40$ & & $4.42 \pm 3.14$ & & $3.89 \pm 2.62$ & \\
\hline \multicolumn{7}{|c|}{$\begin{array}{l}\text { Did you suffer money constrains } \\
\text { during lock down and pandemic? }\end{array}$} \\
\hline Yes $(n=122)$ & $5.76 \pm 3.13$ & 0.269 & $4.63 \pm 3.13$ & 0.074 & $4.20 \pm 2.46$ & 0.400 \\
\hline No $(n=128)$ & $5.30 \pm 3.49$ & & $3.93 \pm 3.03$ & & $3.92 \pm 2.81$ & \\
\hline \multicolumn{7}{|c|}{$\begin{array}{l}\text { Do you have past history of } \\
\text { anxiety/ depressive disorder? }\end{array}$} \\
\hline Yes (n=23) & $5.96 \pm 3.24$ & 0.514 & $6.48 \pm 3.11$ & $<0.001$ & $4.65 \pm 2.38$ & 0.262 \\
\hline No $(n=227)$ & $5.48 \pm 3.33$ & & $4.05 \pm 3.01$ & & $4.00 \pm 2.67$ & \\
\hline \multicolumn{7}{|c|}{$\begin{array}{l}\text { Did you suffer from anxiety/ } \\
\text { depressive symptoms during the } \\
\text { pandemic? }\end{array}$} \\
\hline Yes $(n=180)$ & $5.65 \pm 3.27$ & 0.338 & $4.03 \pm 2.99$ & 0.045 & $4.19 \pm 2.39$ & 0.199 \\
\hline No $(n=70)$ & $5.21 \pm 3.45$ & & $4.90 \pm 3.28$ & & $3.71 \pm 3.20$ & \\
\hline
\end{tabular}

Values are presented as mean \pm standard deviation.

PSS-4, perceived stress scale-4. 


\section{Obstetrics \& Gynecology Science}

Parul Jaiswal, et al. Suspension of fertility services

the time when restrictions were imposed in the country.

\section{Correlation of clinical and psychosocial variables with psychological morbidity}

Table 2 describes the results of the inter-group comparison of participants based on their clinical and psychosocial variables and concerns regarding treatment during the pandemic and PSS-4 scores. The average PSS-4 score was 7.8 80.71 . A small set of participants (9.2\%) reported a past diagnosis of anxiety disorders or depression; however, $72 \%$ of the participants reported experiencing new-onset anxiety symptoms at the time of evaluation. Of these, $81.43 \%$ had lower SES (class IVN) $(P<0.001)$ (Fig. 1A).

On a scale of 1 to $10,21.6 \%$ of the participants were anxious about getting infected with COVID-19 $(4.06 \pm 3.28 ; 95 \%$ $\mathrm{Cl}, 3.65-4.46)$. Those with a history of anxiety or depressive

A

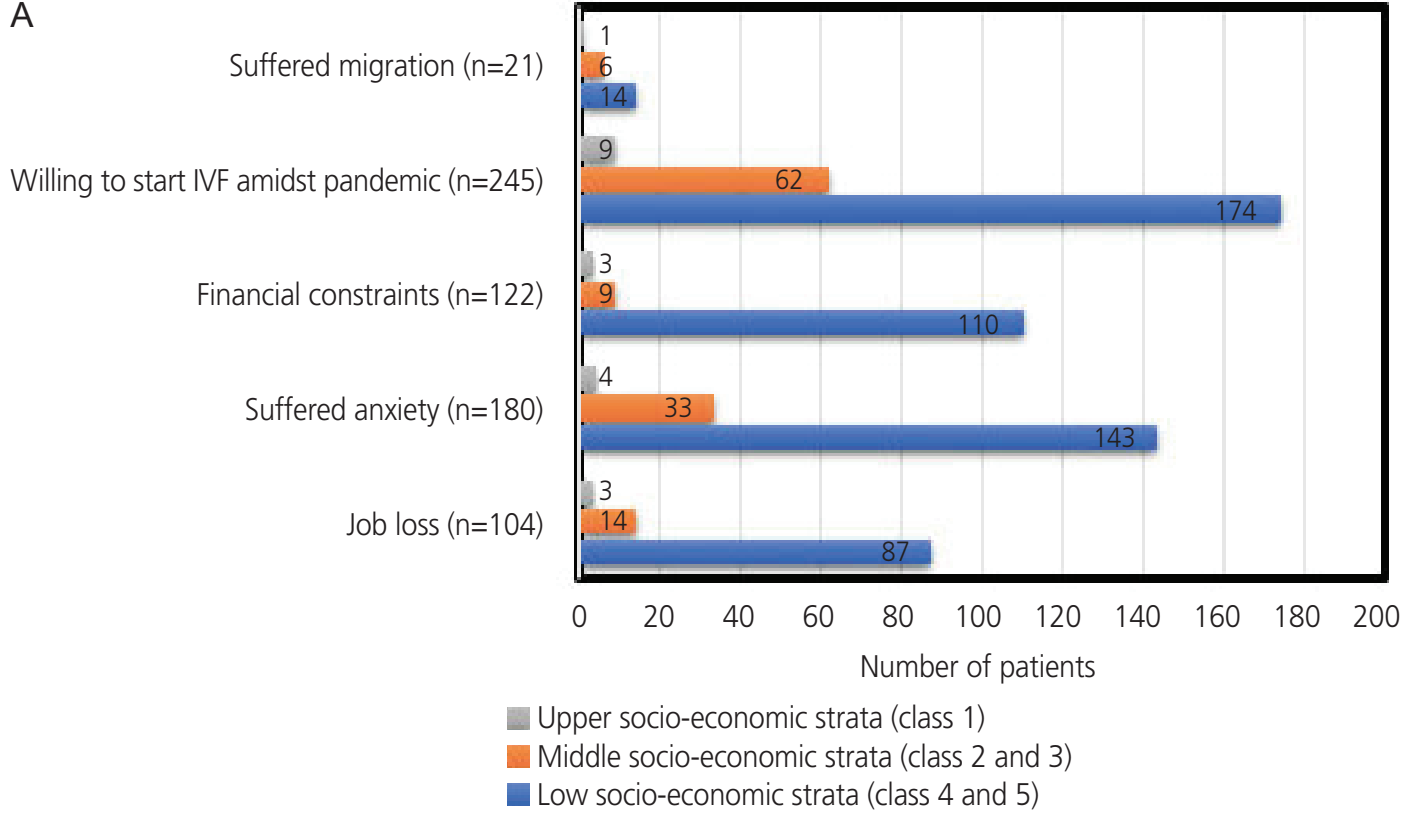

B

Correlation between age and score on delay in infertility treatment

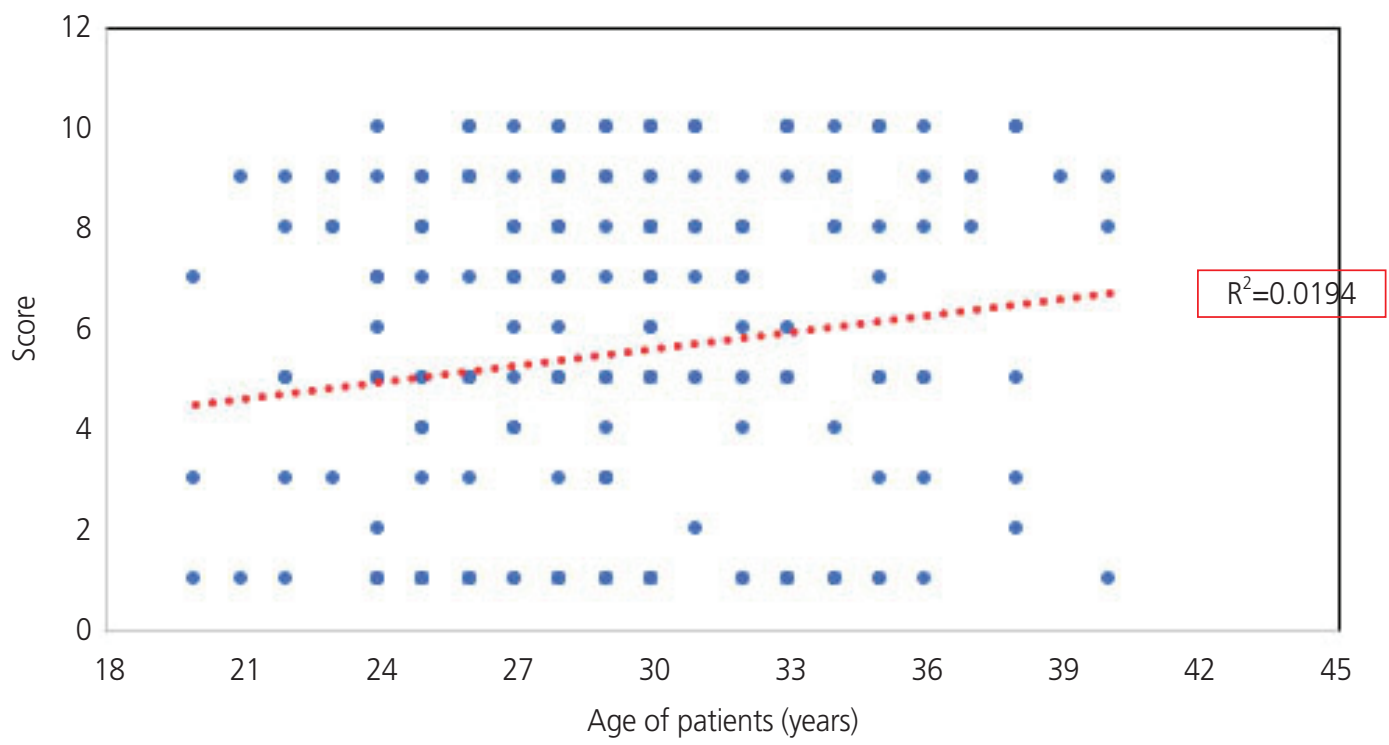

Fig. 1. (A) Correlation of psychosocial factors with socio-economic status. (B) Correlation of increasing age with self-reported anxiety due to delay in treatment. IVF, in-vitro fertilisation. 


\section{Obstetrics \& Gynecology Science}

Vol. 65, No. 2, 2022

disorders $(P<0.001)$ and those experiencing current depressive and anxiety symptoms ( $P=0.045)$ were significantly more likely to experience anxiety about contracting COVID-19 infection during their hospital visits for infertility treatment. Those who suffered migration were significantly more likely to perceive stress due to the current situation $(P=0.021)$.

\section{Socio-economic impact of pandemic}

Approximately $42 \%$ of the study participants suffered job loss, with nearly half of them having a lower SES (class IVN) $(P=0.001)$. Almost half (48.8\%) reported financial constraints during lockdown, and a significant proportion of this group $(62.5 \%)$ had a lower SES $(P<0.001)$ (Fig. 1A).

Overall, $91.2 \%$ expressed concern about the lack of social support in pregnancy due to COVID-related restrictions, $71.9 \%$ of whom had lower SES ( $P=0.01)$. On a scale of $1-10$, approximately $92.2 \%$ of participants mentioned full support from their spouse to cope with infertility treatment and its delay $(9.65 \pm 1.20 ; 95 \% \mathrm{Cl}, 9.50-9.80)$. The degree of spousal support was significantly correlated with lower PSS-4 scores $(r=-0.30, P<0.01)$.

\section{Impact of pandemic on treatment seeking}

The top three concerns during the pandemic were infertility and treatment delay (48.4\%), job loss (19.2\%), and risk of contracting COVID-19 infection (16\%).

On a scale of 1 to 10 , about $20 \%$ of participants were 'extremely anxious' about the delay in infertility treatment due to suspension of elective service $(5.52 \pm 3.32 ; 95 \% \mathrm{Cl}, 5.11$ 5.94). Anxiety levels varied significantly among the various SES groups $(P<0.001)$. Bivariate correlation analysis showed that there was a significant positive correlation between participant age and anxiety levels due to delay in treatment $(r=0.153, P<0.05)$ (Fig. 1B).

On a scale of 1 to $10,12 \%$ were 'extremely anxious' about the effect of infection on embryo development and pregnan-

Table 3. Significant variables that explained variation in PSS-4 and self-reported anxiety scores by multiple linear regression analysis

\begin{tabular}{|c|c|c|c|c|c|c|c|c|c|c|}
\hline \multirow[b]{2}{*}{ Variable } & \multicolumn{5}{|c|}{ PSS-4 } & \multicolumn{5}{|c|}{ Self-reported anxiety scores } \\
\hline & $\begin{array}{l}\text { Regression } \\
\text { coefficient }\end{array}$ & SE & $\begin{array}{l}\text { Std. } \\
\text { regression } \\
\text { coeff. }\end{array}$ & $P$-value & $\begin{array}{c}\mathbf{R}^{2}- \\
\text { explained }\end{array}$ & RE & SE & $\begin{array}{l}\text { Std. } \\
\text { regression } \\
\text { coeff. }\end{array}$ & $P$-value & $\begin{array}{c}\mathbf{R}^{2}- \\
\text { explained }\end{array}$ \\
\hline Constant & 0.41 & 0.24 & & 0.096 & 0.994 & 2.73 & 0.66 & & $<0.001$ & 0.694 \\
\hline $\begin{array}{l}\text { Worry due } \\
\text { suspension of } \\
\text { fertility services }\end{array}$ & 1.02 & 0.01 & 0.63 & $<0.001$ & & 0.42 & 0.02 & 0.63 & $<0.001$ & \\
\hline $\begin{array}{l}\text { Worry about getting } \\
\text { COVID infection }\end{array}$ & 0.97 & 0.01 & 0.59 & $<0.001$ & & 0.25 & 0.03 & 0.38 & $<0.001$ & \\
\hline $\begin{array}{l}\text { Partner help to cope } \\
\text { with infertility } \\
\text { stress }\end{array}$ & 1.02 & 0.02 & 0.23 & $<0.001$ & & -0.16 & 0.07 & -0.09 & 0.013 & \\
\hline $\begin{array}{l}\text { Duration of } \\
\text { infertility }\end{array}$ & 0.09 & 0.04 & 0.01 & 0.038 & & & & & & \\
\hline
\end{tabular}

PSS-4, perceived stress scale-4; SE, standard of error; Std., standard; RE, regression co-efficient; COVID, coronavirus disease.

Table 4. Variables for self-reported anxiety by logistic regression analysis (forward likely Hood method)

\begin{tabular}{lcccc}
\hline \multirow{2}{*}{ Variable } & Adjusted OR & P-value & \multicolumn{2}{c}{$\mathbf{9 5 \% \mathrm { Cl }}$} \\
\cline { 4 - 5 } & & & Lower & Upper \\
\hline Duration of infertility & 1.65 & 0.039 & 1.03 & 2.67 \\
Worry due to suspension of fertility services & 1.20 & 0.027 & 1.02 & 1.41 \\
Worry about getting COVID infection & 0.81 & $<0.001$ & 0.72 & 0.90 \\
Constant & 1.33 & 0.545 & & \\
\hline
\end{tabular}

$\mathrm{OR}$, odds ratio; Cl, confidence interval; COVID, coronavirus disease. 


\section{Obstetrics \& Gynecology Science}

Parul Jaiswal, et al. Suspension of fertility services

cy $(2.62 \pm 2.855 ; 95 \% \mathrm{Cl}, 2.26-2.98)$. Similarly, a small proportion of participants (14\%) were 'extremely anxious' about infection risk due to frequent hospital visits during pregnancy (2.86 $2.976 ; 95 \% \mathrm{Cl}, 2.49-3.23)$.

The majority of the participants (98\%) wished to restart infertility treatment despite the pandemic, and a significant proportion (71.02\%) of these patients had lower SES $(P<0.001)$. The main reasons reported to restart treatment were worry about increasing age $(77.2 \%)$ and emotional disturbance due to treatment delay (70.4\%). Approximately $29 \%$ reported family pressure as the key reason, while $4.4 \%$ reported domestic violence as the reason. In the subgroup whose IVF treatment had been interrupted by COVID-19, $91.6 \%$ were willing to undergo IVF and embryo transfer in the same cycle, $5.6 \%$ were willing to wait until the pandemic subsided, and $2.8 \%$ wanted to opt for egg freezing and transfer after the pandemic.

Patients who were worried about getting COVID-19 infection were reluctant to visit the hospital for the same reason $(r=0.651, P<0.001)$. Multiple linear regression was used to calculate the significant predictors of PSS-4 and anxiety (Table 3). Logistic regression analysis using the forward likelihood method showed that duration of infertility, fear of getting infected with COVID-19, and worry about delay in fertility services each had a significant impact on whether the participant reported experiencing anxiety at the time of evaluation (Table 4).

\section{Discussion}

The present study is unique in that it focuses on an LMIC, where internal migration was a major event during the pandemic. We assessed the psychological impact of treatment postponement/suspension on infertile women waiting for various fertility treatments during the pandemic. The findings indicate that the duration of infertility, worry due to suspension of fertility services, and worry about COVID-19 infection are significant predictors of psychological morbidity among infertile women. The study also highlights that although the women belonging to lower SES suffered more job loss, migration, and financial constraints and had significantly higher self-reported anxiety scores due to suspension of treatments, the majority of them wished to resume treatment amidst the pandemic.
The response rate in this study was comparable to previously reported response rates in these types of surveys [13]. We could reach a response rate of $>50 \%$ because the link was sent to patients on a one-to-one basis during teleconsultation calls or when they visited the OPD.

Like other global crises, this pandemic has affected the mental health of the general global population, leading to moderate to severe anxiety, as reported in early studies in China [14]. A recent meta-analysis reported that the prevalence of anxiety among infertile women was $36.17 \%$, and this prevalence was significantly higher in the low-middle income population (54.24\%) than in the high-income population (25.05\%) [15]. Suspension of fertility services has led to aggravated anxiety and apprehension among infertile and pregnant women [16], and infertility has been reported as a top stressor even during the pandemic [17]. We observed that the prevalence of self-reported anxiety symptoms at the time of completing the survey was $72 \%$.

Financial distress due to the pandemic has a significant correlation with poorer mental health according to a longitudinal survey of Australians during the early phase of the pandemic [18]. Among people who suffered internal migration during the pandemic in India, almost half were female, and most of these belonged to lower SES classes [7]. Given that the study setting is an LMIC, the financial impact of the pandemic was felt more intensely, and it is likely that this played a key role in driving up the rate of self-reported anxiety by participants at the time of the survey [19].

Our initial survey among infertile women was conducted to evaluate their views and perceptions without assessing the psychological impact of treatment suspension using any tools. In this survey, $90 \%$ of participants wanted immediate resumption despite the pandemic, and advancing age was reported as the most important reason for requesting ART services [11]. The current survey, which was conducted in a separate population subset when uncertainty regarding the pandemic had worsened and the wait had been extended beyond 6 months, reported a linear correlation between increasing age and anxiety experienced due to treatment suspension.

One study reported a disagreement between the infertile population and suspension guidelines, and $82 \%$ reported that income loss during the pandemic would not affect their plan to resume treatment [20]. Despite suffering from job loss, migration, and financial constraints, $98 \%$ of the partici- 


\section{Obstetrics \& Gynecology Science}

Vol. 65 , No. 2, 2022

pants in the present survey wished to restart treatment.

This survey was conducted when the ART treatment was suddenly stopped due to a nationwide lockdown, which was a shock to everyone but particularly for infertile couples who were consulting for fertility treatment. Additionally, it is worth mentioning that their employment was also jeopardized due to the lockdown since the majority of participants worked on a small scale or as employees/laborers in the private sector on a daily wage basis. Therefore, treatment delay during lockdown was a major reason for their anxiety and occurred irrespective of personal or economic factors.

Studies from Western countries have reported that patients with higher COVID-related anxiety display unwillingness to resume treatment $[20,21]$. In contrast, we found that delay/ suspension of treatment was a major predictor of stress and anxiety, and participants wished to resume treatment despite the presence of COVID-related anxiety. This finding may explain the emotional burden experienced by this population due to societal pressures and the fact that the COVID-19 pandemic has only worsened our population's mental health and quality of life.

In a study of infertile Italian women, $64.6 \%$ wished to restart treatment and 29\% were uncertain and wanted more evidence on the effect of COVID-19 on treatment and pregnancy [9]. However, almost all participants in our study wished to resume treatment, irrespective of knowledge of the effect of COVID-19 on pregnancy outcome.

Social support has been shown to have a significant effect on the social functioning of individuals, thus reducing stress and anxiety levels [22]. Our study reported significantly lower PSS scores among women who received social support from their spouses. Similarly, a survey of American women whose fertility treatment was paused during the pandemic showed that those with stronger support systems and who employed effective coping strategies to deal with the treatment delay demonstrated more resilience, less perceived stress, and less anxiety [23]. Coping strategies can be taught to affected women by creating liaisons with mental health professionals in anticipation of further treatment interruptions.

One limitation of the study is that this was a single-center study, which was conducted at a tertiary care referral center; thus, it may not be reasonable to generalize the results. In this study, we relied only on self-reported anxiety symptoms instead of a validated questionnaire to screen for anxiety. In addition, we could not interview male partners, hence their views on this topic could not be recorded accordingly. Another limitation was that those with other mental disorders, such as psychotic illnesses, were not excluded from the study. More emotional breakdowns are expected in women who are already diagnosed with psychiatric disorders. This cohort has to be given importance in the study since their scores matter more and are most affected by the suspension of ART services.

The study was stopped 3 months after the first recruitment due to the rapidly evolving pandemic situation. Like most other countries, India suffered an intense second wave that resulted in the closure of partially opened elective services [24]. Since this study was completed earlier, we can anticipate worsening psychological morbidity among the infertile population, leaving them hopeless and incapacitated due to the multiple psychosocial effects of this pandemic. The social stigma of infertility is compounded by emerging mental health issues, especially among Indian women who are economically disadvantaged [25]. Further, the COVID-19 pandemic has had a global effect on outlooks and perspectives towards life. Hence, clinicians and fertility specialists should gain insight into this aspect and use empathetic communication skills to build a rapport. Stepwise opening of ART services might have helped in mitigating some anxiety; however, they have not been fully opened because of the need to employ COVID-19 appropriate behavior and limited appointments in the clinic to avoid crowding. Therefore, the majority of infertile women are still uncertain and anxious about the limited resumption of ART services. Additional pandemic waves might occur and result in further lockdowns that delay treatment. Routine screening may be carried out to identify women who need further management of mental health issues.

To conclude, there is a need to assess the psychological health of infertile women who are waiting for the resumption of fertility treatment as the second pandemic wave will further affect the mental health of this vulnerable population.

\section{Conflict of interest}

No potential conflict of interest relevant to this article was reported. 


\section{Obstetrics \& Gynecology Science}

Parul Jaiswal, et al. Suspension of fertility services

\section{Ethical approval}

The study was started after ethical approval.

\section{Patient consent}

Particiapnts were given brief information about the study in the begining of questionniare. Only those willing to particiapte in the study, proceeded to fill the questionniare.

\section{Funding information}

None.

\section{Acknowledgments}

We acknowledge the participation of the patients who took time to complete this survey and helped us to carry out this research.

\section{References}

1. World Health Organization. WHO Director-General's opening remarks at the mission briefing on COVID-19 [Internet]. Geneva (CHE): WHO; c2020 [cited 2021 May 10]. Available from: https://www.who.int/dg/speeches/ detail/who-director-general-s-opening-remarks-at-themission-briefing-on-COVID-19.

2. American Society for Reproductive Medicine. Patient management and clinical recommendations during the coronavirus (COVID-19) pandemic [Internet]. Washington, D.C. (USA): American Society for Reproductive Medicine; c2020 [cited 2021 May 10]. Available from: https://www.asrm.org/globalassets/asrm/asrm-content/ news-and-publications/covid-19/covidtaskforce.pdf.

3. Ćosić K, Popović S, Šarlija M, Kesedžić I. Impact of human disasters and COVID-19 pandemic on mental health: potential of digital psychiatry. Psychiatr Danub 2020;32:25-31.

4. Slade P, O'Neill C, Simpson AJ, Lashen H. The relationship between perceived stigma, disclosure patterns, sup- port and distress in new attendees at an infertility clinic. Hum Reprod 2007;22:2309-17.

5. El Kissi Y, Romdhane AB, Hidar S, Bannour S, Ayoubi Idrissi $\mathrm{K}$, Khairi $\mathrm{H}$, et al. General psychopathology, anxiety, depression and self-esteem in couples undergoing infertility treatment: a comparative study between men and women. Eur J Obstet Gynecol Reprod Biol 2013;167:185-9.

6. Lorant V, Deliège $D$, Eaton W, Robert A, Philippot P, Ansseau M. Socioeconomic inequalities in depression: a meta-analysis. Am J Epidemiol 2003;157:98-112.

7. Irudaya Rajan S, Sivakumar P, Srinivasan A. The COVID-19 Pandemic and internal labour migration in india: a 'crisis of mobility'. Indian J Labour Econ 2020;63:102139.

8. Boivin J, Harrison C, Mathur R, Burns G, PericleousSmith A, Gameiro S. Patient experiences of fertility clinic closure during the COVID-19 pandemic: appraisals, coping and emotions. Hum Reprod 2020;35:2556-66.

9. Esposito V, Rania E, Lico D, Pedri S, Fiorenza A, Strati MF, et al. Influence of COVID-19 pandemic on the psychological status of infertile couples. Eur J Obstet Gynecol Reprod Biol 2020;253:148-53.

10. Roy KK, Rai R, Zangmo R, Kumari A, Noor N, Garg D. Laparoscopic gynecological surgery in COVID-19 pandemic. Obstet Gynecol Sci 2021;64:322-6.

11. Gupta $M$, Jaiswal $P$, Bansiwal $R$, Sethi $A$, Vanamail $P$, Kachhawa $G$, et al. Anxieties and apprehensions among women waiting for fertility treatments during the COVID-19 pandemic. Int J Gynaecol Obstet 2021;152:4413.

12. Wani RT. Socioeconomic status scales-modified Kuppuswamy and Udai Pareekh's scale updated for 2019. J Family Med Prim Care 2019;8:1846-9.

13. Turocy J, Robles A, Hercz A, D'Alton M, Forman E, Williams $Z$. The emotional impact of the ASRM guidelines on fertility patients during the COVID-19 pandemic [Internet]. Fertility and Sterility; c2020 [cited 2021 May 19]. Available from: https://www.fertstertdialog.com/ posts/65837-the-emotional-impact-of-the-asrm-guidelines-on-fertility-patients-during-the-covid-19-pandemic.

14. Wang C, Pan R, Wan X, Tan Y, Xu L, Ho CS, et al. Immediate psychological responses and associated factors during the initial stage of the 2019 coronavirus disease (COVID-19) epidemic among the general population in 


\section{Obstetrics \& Gynecology Science}

Vol. 65, No. 2, 2022

China. Int J Environ Res Public Health 2020;17:1729.

15. Kiani Z, Simbar M, Hajian S, Zayeri F, Shahidi M, Saei Ghare Naz M, et al. The prevalence of anxiety symptoms in infertile women: a systematic review and meta-analysis. Fertil Res Pract 2020;6:7.

16. Durankuş F, Aksu E. Effects of the COVID-19 pandemic on anxiety and depressive symptoms in pregnant women: a preliminary study. J Matern Fetal Neonatal Med 2022;35:205-11.

17. Vaughan DA, Shah JS, Penzias AS, Domar AD, Toth TL. Infertility remains a top stressor despite the COVID-19 pandemic. Reprod Biomed Online 2020;41:425-7.

18. Dawel A, Shou Y, Smithson M, Cherbuin N, Banfield M, Calear AL, et al. The effect of COVID-19 on mental health and wellbeing in a representative sample of australian adults. Front Psychiatry 2020;11:579985.

19. Blake P, Wadhwa D. 2020 year in review: the impact of COVID-19 in 12 charts [Internet]. Washington, DC (USA): World Bank Blog; c2020 [cited 2021 Jul 18]. Available from: https://blogs.worldbank.org/voices/2020-yearreview-impact-covid-19-12-charts.

20. Marom Haham L, Youngster M, Kuperman Shani A, Yee S, Ben-Kimhy R, Medina-Artom TR, et al. Suspension of fertility treatment during the COVID-19 pandemic: views, emotional reactions and psychological distress among women undergoing fertility treatment. Reprod Biomed Online 2021;42:849-8.

21. Ben-Kimhy R, Youngster M, Medina-Artom TR, Avraham $S$, Gat I, Marom Haham L, et al. Fertility patients under COVID-19: attitudes, perceptions and psychological reactions. Hum Reprod 2020;35:2774-83.

22. Erdem K, Ejder Apay S. A sectional study: the relationship between perceived social support and depression in Turkish infertile women. Int J Fertil Steril 2014;8:303-14.

24. Seifer DB, Petok WD, Agrawal A, Glenn TL, Bayer AH, Witt BR, et al. Psychological experience and coping strategies of patients in the Northeast US delaying care for infertility during the COVID-19 pandemic. Reprod Biol Endocrinol 2021;19:28.

24. Pandey V, Nazmi S. Covid-19 in India: why second coronavirus wave is devastating [Internet]. London (UK): BBC News; c2021 [cited 2021 May 20]. Available from: https://www.bbc.com/news/world-asia-india-56811315.

25. Roberts L, Renati S, Solomon S, Montgomery S. Women and infertility in a pronatalist culture: mental health in the slums of mumbai. Int I Womens Health 2020;12:993-1003. 